Bryn Mawr College

Scholarship, Research, and Creative Work at Bryn Mawr College

Graduate School of Social Work and Social

Graduate School of Social Work and Social

Research Faculty Research and Scholarship

Research

2006

\title{
Correlates of Problem Recognition and Intentions to Change among Caregivers of Abused and Neglected Children
}

Julia H. Littell

Bryn Mawr College, jlittell@brynmawr.edu

Heather Girvin

Let us know how access to this document benefits you.

Follow this and additional works at: http://repository.brynmawr.edu/gsswsr_pubs

Part of the Social Work Commons

\section{Custom Citation}

Littell, Julia H., and Heather Girvin. "Correlates of Problem Recognition and Intentions to Change among Caregivers of Abused and Neglected Children." Child Abuse \& Neglect 30, no. 12 (2006): 1381-1399, doi: 10.1016/j.chiabu.2006.08.004.

This paper is posted at Scholarship, Research, and Creative Work at Bryn Mawr College. http://repository.brynmawr.edu/gsswsr_pubs/33

For more information, please contact repository@brynmawr.edu. 


\title{
Correlates of Problem Recognition and Intentions to Change \\ Among Caregivers of Abused and Neglected Children
}

\author{
Julia H. Littell \\ Graduate School of Social Work and Social Research \\ Bryn Mawr College \\ Bryn Mawr, PA \\ and \\ Heather Girvin \\ Department of Social Work \\ School of Humanities and Social Science \\ Millersville University \\ Millersville, PA
}

Running head: Problem Recognition and Intentions to Change

Key Words: Readiness for change, motivation, intentions, problem recognition, denial

Address correspondence to:

Julia H. Littell, Ph.D., Associate Professor

Graduate School of Social Work and Social Research

Bryn Mawr College

300 Airdale Road

Bryn Mawr, PA 19010

610/520-2619 voice

610/520-2655 fax

jlittell@brynmawr.edu

We thank Leslie B. Alexander and William W. Reynolds for helpful comments on an earlier version of this paper. John R. Schuerman and Ronna Cook provided valuable assistance in the development and implementation of this study. 


\section{Practice Implications}

This study shows that caregivers' problem recognition (PR) and intentions to change (ITC) are separate dimensions of readiness for change that relate to different case characteristics and may be affected by caseworkers' experience and contacts in different ways. Clinicians should assess PR and ITC in relation to specific parenting problems and contexts, rather than using general categories or stages of change to describe caregivers. ITC should not be confused with willingness to work with a particular caseworker or participate in a particular program. 


\begin{abstract}
Objective: To identify individual, family, and caseworker characteristics associated with problem recognition (PR) and intentions to change (ITC) in a sample of caregivers who received in-home child welfare services following substantiated reports of child abuse or neglect.
\end{abstract}

Methods: Caregivers were interviewed at 4 weeks, 16 weeks, and 1 year after referral for inhome services. In these interviews, the University of Rhode Island Change Assessment scale assessed PR and ITC in relation to caregiving practices. Additional data were obtained from administrative records and surveys of in-home services caseworkers. We used growth models to identify caregiver, family, and caseworker characteristics associated with initial levels of PR and ITC, and with changes in PR and ITC over time.

Results: Contrary to expectations, there were no overall increases in PR and ITC during the first 4 months of in-home services. PR and ITC scores fluctuated over time, in relation to some external events, case characteristics, and caseworker characteristics; however, we were able to account for small portions of the variance in PR and ITC. Controlling for social desirability bias and other variables in the analysis, negative life events, lack of network support, and the severity of caregiver depression were associated with greater PR; housing problems were associated with lower PR. Caregiver depression and age were associated with ITC. Caregivers whose children had been removed from their homes showed significant increases in ITC in the first few months 
of in-home services. The duration of caseworkers' child welfare experience predicted increases in their clients' PR in the first 4 months and more frequent contacts with an experienced caseworker predicted small, but significant increases in ITC over time.

Conclusions: PR and ITC are associated with somewhat different case characteristics and may be affected by caseworkers' experience. 
Practitioners frequently consider caregivers' readiness for change in their assessments and decisions in cases of child abuse and neglect. Gelles $(1995,1996,2000)$ and others view caregivers' readiness for change as an important component of risk assessment, case planning, and allocation of treatment and out-of-home placement resources. However, there is little empirical research on readiness for change among parents and other primary caregivers of abused and neglected children. In this paper, we identify caregiver, family, and caseworker characteristics that are associated with two components of readiness for change: problem recognition and intentions to change.

\section{Readiness for Change}

Readiness for change has been conceptualized in several ways. It has been described as a single continuum (e.g., of “motivation;” Carey, Purnine, Maisto, \& Carey, 1999; Davidson, 1998; Sutton, 1996; Project MATCH Research Group, 1997; Weinstein, Rothman \& Sutton, 1998); as a function of distinct affective, cognitive, and/or behavioral processes (e.g., Bandura 1997, 1998; Miller \& Tonigan, 1996); and as an underlying concept in the popular "stages of change" model (DiClemente \& Prochaska, 1998; Prochaska \& DiClemente, 1984, 1986, 1992, 1998). Single, continuous measures of motivation have not been consistent predictors of outcomes or treatmentmatching effects in treatment for alcoholism (Project MATCH Research Group, 1997). Investigators have identified multiple dimensions of readiness (Hemphill \& Howell, 2000; Isenhart, 1994; Miller \& Tonigan, 1996), but these dimensions are not consistent across studies. Recent reviews of the voluminous literature on stages of change suggest that there is little evidence for the stage model (Carey et al., 1999; Littell \& Givin, 2002) or the effectiveness of stage-based interventions (Reisma et al., 2002). 
In a previous study, we modified the University of Rhode Island Change Assessment (URICA) scale (McConnaughy, Prochaska, \& Velicer, 1983; McConnaughy, DiClemente, Prochaska, \& Velicer, 1989) to assess readiness for change in a sample of primary caregivers of maltreated children. Caregivers completed the URICA at three points in time within 1 year following referral for in-home services. Instead of stages of change or a single continuum, we found two underlying dimensions, which we termed Problem Recognition (PR) and Intentions to Change (ITC) (Littell \& Girvin, 2006). PR and ITC were not significantly correlated in our sample. Some caregivers reported that they had problems caring for their children, but expressed little intent to change; others reported that they did not have caregiving problems, but intended to make improvements in this area; still others reported that they had parenting problems and intended to work on these problems.

Using data from the same sample, a second study examined the predictive validity of PR and ITC (Littell \& Girvin, 2005). Greater PR predicted reductions in subsequent reports of child maltreatment to public child welfare officials. Greater ITC predicted improvements in a few aspects of individual and family functioning and significant reductions in the likelihood that subsequent reports of maltreatment would be substantiated by CPS investigators. An overall measure of readiness for change that included both PR and ITC predicted significant reductions in the risk of out-of-home placement within a 1-year period, although the separate PR and ITC scales did not (Littell \& Girvin, 2005). Although the URICA has important conceptual and methodological limitations (Carey et al., 1999; Littell \& Girvin, 2002), the scales we derived from it appear to measure constructs that are important to practitioners and may have some predictive validity in child welfare samples. 
In the present longitudinal study, we identify factors associated with initial variations and changes over time in caregivers' problem recognition and intentions to change. If PR and ITC are distinct phenomena, as our previous work indicates, they may be related to somewhat different case characteristics and may be influenced by different casework processes.

\section{Correlates of Readiness for Change}

Ripple, Alexander, and Polemis (1964) suggested that motivation for change is a function of "the push of discomfort" and "the pull of hope." In their view, higher levels of motivation arise when people are uncomfortable with the status quo and hopeful that the situation can be improved. They thought that discomfort without hope could be immobilizing. If this is so, then readiness for change should increase with problem severity, external pressure to change, and the availability of effective, feasible remedies. Indeed, previous studies have found that readiness for change varied by the nature and level of distress among clients receiving outpatient mental health services (O’Hare, 1996a) or substance abuse treatment (Velazquez, Carbonari, \& DiClemente, 1999). Different levels of readiness for change were found among voluntary versus court-referred clients of a community mental health center (O’Hare, 1996b). Among caregivers of maltreated children, readiness for change appeared to vary by the severity of caregiver depression and perceived availability of social support (Girvin, 2002).

The literature on client motivation and readiness for change tends to focus on intrapersonal causes and correlates of readiness. However, some authors have noted that motivation for treatment (Miller, 1985) and treatment participation (Kazdin, Holland, \& Crowley, 1997) are affected by clinician and treatment characteristics, external demands and barriers, and by clients' perceptions of the relevance, demands (e.g., difficulty), and efficacy of the treatment. 
Many child welfare practitioners hope their interventions will increase clients' problem recognition and intentions to change, and that these changes will lead to improvements in children's living conditions. Interventions aimed at enhancing client motivation (e.g., Miller \& Rollnick, 2002) are of great interest, but have not been systematically studied in child welfare settings. One study showed that caseworker and service characteristics were associated with systematic variations in client participation in child welfare in-home services; specifically, caseworkers' child welfare experience, caseload size, and intensity of contact with families related to variations in caregiver compliance (Littell \& Tajima, 2000). It is possible that these factors affect caregiver problem recognition and intentions to change.

A few studies have examined associations between measures of readiness for change and social desirability bias. At issue is whether self-report data on readiness for change are distorted by the tendency to deny socially undesirable traits and claim socially desirable ones. Paulhus (1984) noted that social desirability bias has two components: self-deception and otherdeception. He thought that social scientists ought to be more concerned about other-deception (also termed impression management), which is measured by the Marlowe-Crowne scale. Three studies found no significant differences between subjects with different motivational profiles or stage-of-change assessments in terms of their scores on the Marlowe-Crowne Social Desirability Scale (Cardinal, 1997; Isenhart, 1994; Willoughby \& Edens, 1996). In a study of adolescent offenders, three of the four URICA subscales were associated with a measure of self-deceptive enhancement, but none was associated with impression management (Hemphill \& Howell, 2000). Thus, results of four studies suggest that responses to the URICA and similar measures are not systematically distorted by attempts to impress others. 
In sum, readiness for change appears to be related to conditions that produce discomfort and hope. Readiness for treatment (which is not the same as readiness for change) may be affected by client, clinician, and treatment characteristics. There is no evidence that self-reported readiness is distorted by impression management.

To our knowledge, the present study is the first to examine the correlates of problem recognition (PR) and intentions to change (ITC) in a sample of caregivers of abused and neglected children. Since greater PR and ITC predict some improvements in individual and family functioning and reductions in subsequent maltreatment, these two components of readiness for change may be important targets of intervention. Indeed, clinicians try to enhance clients' understandings of their problems and bolster their intentions to change. The present study may contribute to these efforts by generating new knowledge about factors that influence the development and change of PR and ITC.

\section{Hypotheses}

Following Ripple and her colleagues (1964), we expected conditions likely to produce caregiver discomfort to be positively associated with both problem recognition and intentions to change. We expected conditions that could produce or sustain hope to relate to intentions to change, but not problem recognition.

Thus, initial variations in caregiver problem recognition and intentions to change should relate to problem severity, service history, and other case characteristics. More specifically:

- The severity of caregiver depression, housing and economic deficits, and lack of social support (greater discomfort) should be associated with greater problem recognition.

- Younger caregivers might be more open to change (more hopeful) than older parents, and 
have higher ITC scores.

- Caregivers who have more daily hassles (e.g., single heads of households and those with more children) may face more obstacles to change (and have less hope) than other caregivers; hence, their ITC scores may be relatively low.

- Previous encounters with the child welfare system (the number of prior reports of child maltreatment and previous out-of-home placements) might increase discomfort, which may be evident in greater PR and/or ITC at the beginning of treatment.

We expected caregivers' problem recognition and intentions to change to increase in the first few months of in-home services, but it was not clear whether any such increases would be sustained for a full year. Other hypotheses regarding changes in PR and ITC were as follows:

- Recent life events and social support (two potential sources of discomfort and hope) may predict changes in PR and ITC over time.

- The frequency of contact with in-home services caseworkers may be associated with changes in PR and ITC over time (by increasing discomfort and/or hope).

- Caseworkers who have more opportunities to work with caregivers (e.g., those with lower caseloads) and those with greater experience and training may be better able to facilitate increases in PR and ITC among their clients.

\section{Methods}

A longitudinal study of 353 child welfare in-home services cases was conducted in conjunction with the Evaluation of Family Preservation and Reunification Services (EFPRS). The EFPRS was funded by the U.S. Department of Health and Human Services and conducted by Westat, Inc. and its subcontractors, the Chapin Hall Center for Children and James Bell 
Associates (Westat, Inc., 2001, 2002). The EFPRS was conducted in several states and was approved by Westat's Institutional Review Board (IRB). The present study was funded separately from the EFPRS and was considered exempt from review by the Bryn Mawr College IRB, because it relied on secondary analysis of data collected in the EFPRS.

Between March 1997 and June 1999, the Philadelphia Department of Human Services (DHS) identified 353 cases of child abuse and neglect, which were classified as having "moderate risk" of further maltreatment according to risk assessments conducted in a recent CPS investigations. For purposes of the EFPRS, these families were randomly assigned to intensive family preservation services (FPS) or less-intensive Services to Children in their Own Homes (SCOH). Two private agencies provided FPS, and three private agencies provided $\mathrm{SCOH}$ services to families in the evaluation (see Westat, Inc., 2002). Although the FPS programs were more intense (5-10 hours of direct contact per week versus 2 or 3 hours in SCOH) and short-term (3 months versus 6-9 months), both FPS and SCOH were aimed at improving family functioning, reducing risks of subsequent harm to children, and preventing out-of-home placement when appropriate. The EFPRS found no significant differences between FPS and SCOH cases in family-level rates of subsequent child maltreatment or out-of-home placement (Westat, Inc., 2002). There were a few differences in analyses of child and family functioning, but some favored the FPS group and others favored the SCOH group (Westat, Inc., 2002).

Westat staff obtained informed consent and conducted in-person interviews with caregivers at three points in time over a 1-year period following random assignment and referral. Most interviews were conducted in caregivers' homes (for privacy reasons, a few interviews were conducted on porches, in parked cars, or at local fast-food restaurants). Interviewers were 
aware of treatment assignment. On average, initial (Time 1) caregiver interviews occurred 4 weeks after random assignment, interim (Time 2) interviews occurred at 16 weeks, and follow-up (Time 3) interviews were conducted at 1 year after random assignment. Response rates were $75 \%$ at Time 1, 74\% at Time 2, and 64\% at Time 3. Most (88\%) of the caregivers in the study participated in at least one interview; 172 (49\%) participated in all three interviews (Westat, Inc. 2002). Missing data were due to difficulties locating caregivers and scheduling interviews with them. On most (16/17) measures, caregivers who completed follow-up interviews were similar to those who did not; however, the latter group had higher initial scores on a depression inventory (Westat, Inc., 2002).

Caseworker characteristics were obtained on a self-administered questionnaire. Telephone interviews were scheduled with caseworkers at two points in time (Time 1 and Time 2) for every case. FPS and SCOH caseworkers were also expected to complete a 1-page report every time they had in-person contact or significant telephone contact with a family member in an EFPRS case. The "contact report" documented the location and duration of contact, presence of family members and others, specific topics discussed, and types of material aid and other services provided. Caseworker compliance with this measure was very problematic, because these frequent reports were time-consuming. One or more contact reports are available for only $209(59 \%)$ of the 353 cases in the study. While the EFPRS accomplished its main goal (by producing high-quality estimates of the relative effectiveness of FPS and SCOH; Westat, 2002), it was less successful in gathering data on the nuances of service provision.

For purposes of the present study, we decided to limit our analysis to a subsample of 163 cases (46\%) with valid data on all relevant measures. We could have imputed missing values, but 
were not confident that imputation methods (mean values or regression methods) would produce valid estimates of missing data. Results from our analysis are not generalizable to the full EFPRS sample (but generalizability was not a goal of our study).

\section{Measurement}

\section{Readiness for Change}

To assess caregivers' readiness for change, we used a modified version of the University of Rhode Island Change Assessment (URICA) scale. Originally developed for use in research on psychotherapy (McConnaughy et al., 1983, 1989), the URICA is a self-report measure that has been used to assess readiness for change across a range of behaviors from weight reduction and smoking cessation to recovery from alcohol and cocaine addictions (Prochaska et al., 1994). The instrument's four scales are thought to correspond to the precontemplation, contemplation, action, and maintenance stages of change. Responses are provided on a 5-point, fully anchored scale ( $1=$ strongly disagree, $2=$ disagree, $3=$ undecided, $4=$ agree, $5=$ strongly agree). Investigators have modified the URICA for use in research on different populations and problems (see, for example, Rollnick, Heather, Gold, \& Hall, 1992; Miller \& Tonigan, 1996).

Limitations of the URICA and its variants have been discussed at length elsewhere (e.g., by Carey et al., 1999; Davidson, 1998; Jefferson, 1991; Hutchison, 1996; Littell \& Girvin, 2002); these limitations include reliance on a stage model, conflation of readiness for change with readiness to participate in a particular program, and violation of several principles of item and test construction. However, to our knowledge, there are no better measures of readiness for change.

After consultation with one of the developers of the URICA (Carlo DiClemente, 
September 17, 1996), we began with a 24-item version of the URICA (Carbonari, DiClemente, Addy, \& Pollak, 1996), revised the instrument's instructions so that the items refer to "problems you have in taking care of your children" (instead of "your problems"), and eliminated the maintenance items (since these did not appear to be relevant for our sample). This reduced the instrument to 18 items. This modified URICA (available from the first author) was administered in interviews with caregivers at all three points in time.

As shown in a previous analysis, results of principal axis factor analysis indicated that there were two underlying dimensions in caregivers' responses to URICA items (Littell \& Girvin, 2006). Two scales were created to represent these dimensions: Problem recognition (PR) is the mean of reverse-scored precontemplation items (high precontemplation scores $=$ low problem recognition scores). Intentions to change (ITC) is the mean of contemplation and action items.

As indicated above, we performed the main analysis for this study on a subsample of EFPRS cases. There were 258 cases with valid data on PR and ITC at Time 1; 96 of these cases were missing data on other measures in the analysis. A comparison of 163 cases in the main analysis and 95 cases with missing data on other relevant measures showed no significant differences between two groups on Time 1 PR or ITC scores.

\section{Time-varying Predictors}

Life events. For the EFPRS, caregivers were asked whether certain events had occurred in their lives during the past 3 months. This question was asked at all three points in time.

Caregivers' yes-or-no responses were used to create indices of positive life events (from 6 items: got a good job, fell in love, got married, received a special prize or gift, got new appliances or 
furniture, received praise from someone important) and negative life events (from 8 items: lost a job, failed in school or job training, got divorced or separated, had property stolen, was arrested, beaten up, hurt in a bad accident; see Westat, 2002). Both indices were expressed in terms of the proportion of items endorsed (ranging from 0 to 1 ).

Caregiver depression. The 13-item Depression Subscale of the SCL-90-R mental health inventory was used to measure caregiver depression at all three points in time. Responses ranged from $0-4$, where $0=$ not at all, $1=\mathrm{a}$ little bit, $2=$ moderately, $3=$ quite a bit, and $4=$ extremely. Mean scores were used in our analysis. The depression subscale has strong internal consistency in this sample (Chronbach's alphas $>.9$ at all three points in time).

Caseworker contacts. Estimates of numbers of in-person contacts between caseworkers and primary caregivers were developed using data from several sources. We identified contact reports that indicated that the caseworker had face-to-face contact with the primary caregiver and counted the number of these contacts that occurred within three time periods: 1) prior to the first caregiver interview, 2) between the first and second caregiver interviews, and 3) between the second and third interviews. Then we compared these counts with information from the caregiver interviewers. At Time 1, caregivers were also asked how many times they had met with the caseworker in the past 2 weeks (responses range from 0 to 12). At Time 2, they were asked how many times they had met with the caseworker since the last interview (responses range from 0 to 60). At Time 3, they were asked whether they had met with the caseworker at all since the last interview (63\% of the respondents said they had met with their caseworker during this time). We used these caregiver responses in conjunction with caseworker contact reports to estimate the number of contacts that occurred during the three time intervals. Because contacts were under- 
reported by caseworkers, we used the highest number of contacts reported by either the caseworker or caregiver in the time period in question. The estimate is zero only if there are no caseworker contact reports for a given time period and the caregiver indicated that there had been no contact in that period. The estimate is missing if no contact data are available.

\section{Case Characteristics}

Demographic data. Information on the caregiver's age, number and ages of children, and household composition was obtained in initial interviews with caregivers. From this information, we created a dummy variable, which indicates whether the caregiver was a "single parent," defined as the only adult (over age 18) living in the household (not by marital status).

Preliminary analysis showed that caregivers' ages were highly correlated with their children's ages (r>.7), but only the former were related to PR and ITC. Since we could not use both variables in regression-type analyses (without creating multicolinarity problems), we chose to include the caregiver's age in this analysis.

Social desirability bias. The 13-item version of the Marlowe-Crowne Social Desirability Scale (Reynolds, 1982) was included in caregiver interviews. Only one of the two subscales--the denybad scale--had acceptable psychometric properties in this sample (Kuder-Richardson formula $20(\mathrm{KR}-20) \mathrm{r}=.67$ to .73$)$. This subscale measures the tendency to deny socially undesirable traits, which was relatively common in this sample. Deny-bad scores were negatively associated with caregiver reports on parent and child problems (Littell \& Reynolds, 2002). Standardized denybad scores (mean $=0, \mathrm{sd}=1$ ) were used in this analysis.

Prior child maltreatment and out-of-home placement. Information on official reports of child maltreatment, the findings of investigations of those reports, and out-of-home placements 
was derived from computerized databases developed and maintained by DHS. From these data, we computed the number of child maltreatment reports that were filed in each case prior to random assignment and were substantiated by a CPS investigation. We created a dummy variable to indicate whether the caregiver had one or more children removed from the home in the past.

Social networks. Network size was defined as the number of family members (parents, brother, and sisters) and friends with whom the caregiver has contact at least once a month. Social network support is the proportion of these network members upon whom the caregiver can rely for emotional support, material aid, or advice.

Housing and economic problems. A measure of housing problems was derived from responses to 10 items that describe problems with heat, appliances, electricity, plumbing, building structure, and crowded or unsafe conditions in caregivers' homes during the three months prior to the interview (KR-20 $\mathrm{r}>.7$ at all three points in time). An index of economic problems was created from four items (difficulty paying for rent, bills, food, or clothing; KR-20 r $>=.67$ ). As with life events, these measures were expressed as the proportion of items endorsed.

\section{Caseworker Characteristics}

On self-administered surveys, caseworkers reported the number of years of child welfare work experience they had, whether they received any graduate-level training, and their "usual" caseload size.

\section{Analysis}

Since there were multiple observations per case and multiple cases per caseworker, the data were nested in a three-level hierarchical structure (level $1=$ time of the observation, level 2 $=$ the case, level $3=$ the casewoker). Hierarchical linear models (HLMs) are designed to handle 
such clustered data. We used growth models (a class of HLMs), which are appropriate for analyses of repeated measures with missing data (Bryk \& Raudenbush, 2002; Raudenbush, Bryk, Cheong, \& Congon, 2001).

The simplest HMLs are used to determine how much of the variance in a repeated measure is attributed to change over time within cases (level 1), differences between cases (level 2), and differences between caseworkers (level 3). We used simple ("fully unconditional") HLMs to partition the variance in PR and ITC into these levels.

More complex ("conditional") HLMs include predictor variables at each level in order to identify correlates of a criterion variable. We used piecewise linear growth models (Bryk \& Raudenbush, 2002) to identify correlates of PR and ITC and predictors of change over time in these measures. "Piecewise" growth models allow us to examine the direction and magnitude of changes in these measures during different time intervals (Time 1 to Time 2, Time 2 to Time 3 ) without assuming that the direction or slope of change would be constant across intervals. As indicated above, we assumed that PR and ITC might increase over the first 4 months of in-home services, but did not expect that increase (slope) to remain constant during the rest of the year.

There were up to three records per case (at level 1), one record for each completed caregiver interview. In the growth models, two dummy variables represent the time of observation in the level 1 equation. Time 1 is the omitted category, represented by the base model (case mean). The coefficient for Time $2(\operatorname{coded} 1=$ Time 2 or Time $3,0=$ Time 1$)$ represents change in the criterion variable from Time 1 to Time 2, while the coefficient for Time $3(1=$ Time 3, $0=$ Time 1 or Time 2$)$ represents change between Time 2 and Time 3. Some timevarying predictors were also included at level 1 ; these include: the number of recent caseworker 
contacts, recent negative life events, and the current caregiver depression score.

Case-level (level 2) predictors include caregiver and family characteristics that were measured at Time 1. We examined associations between these predictors and initial measures of the criterion variable (i.e., the base rate). We also examined their associations with change in the criterion variable from Time 1 to Time 2 and from Time 2 to Time 3 (i.e., their effects on the slopes for the level 1 dummy variables Time 2 and Time 3).

Caseworker characteristics (level 3) included child welfare experience, graduate education, and caseload size. We examined associations between these predictors and initial measures of PR and ITC, and change over time in the criterion variables. We also explored potential interactions between caseworker characteristics and the frequency of contact; to do this, caseworker characteristics were on the slope.

For this analysis, the PR and ITC scales were converted to standardized z-scores (mean $=0, \mathrm{sd}=1)$. Standardized scores are redistributed around the sample means, which are different for different scales. Standardized scores have no clear substantive meaning, because links to the original anchors (such as "strongly agree" or "undecided") have been severed. Zscores are interpreted in terms of differences (in both direction and magnitude) from the sample mean. This serves the purposes of the present analysis, which focuses on potential sources of within-sample variations.

For ease of interpretation, all interval-level predictors were centered around their grand means and dummy variables were uncentered (for an explanation, see Bryk \& Raudenbush, 2002). After all predictors were entered, backward elimination was used to remove variables that were not significant at $\mathrm{p}<.1$. However, to guard against social desirability bias, denybad scores 
remained in the base rate model, regardless of their significance level. Predictors of change to Time 2 or Time 3 also remained in the model for the base rate (regardless of whether they were related to the base rate) in order to examine these interaction effects (interactions with time).

Results

\section{Descriptive Data}

PR and ITC scores were not correlated at any point in time $(r<.15, \mathrm{p}>.05)$. Average PR scores were about 3.6 and ITC scores were close to 4 on the 5-point scale (see Table 1). The PR and ITC scales have acceptable levels of internal consistency (Chronbach's alphas range from .65 to .91 ; Table 1$)$.

\section{[insert Table 1]}

There were 423 observations on 163 cases (over three waves) served by 44 caseworkers. Predictor variables (shown in Table 2) and other descriptive data are described below.

$$
\text { [insert Table 2] }
$$

\section{Case characteristics}

All of the primary caregivers were referred for in-home services following substantiated reports of child abuse or neglect. The families in this study had an average of 1.19 prior, substantiated reports of maltreatment $(\mathrm{sd}=.93$, range $=0$ to 5$)$. About one-fifth $(18 \%)$ of the families had prior out-of-home placements of children.

Of the primary caregivers who participated in initial interviews, $81 \%$ were AfricanAmerican, and 95\% were female. Most caregivers (90\%) were unmarried, and more than half (53\%) were the only person over age 18 in their household. On average, caregivers were 32 years old. They had an average of 3.4 children, ranging in age from newborn to 18 . 
On average, caregivers in this sample had monthly contact with approximately 5 family members and/or friends at Time 1 (the range is 0 to $12, \mathrm{sd}=2.46$ ) and reported that $81 \%$ of their network members provided some form of support at Time 1 (mean=.81, sd=.28).

Most (83\%) of the caregivers were unemployed, approximately $70 \%$ were receiving welfare benefits (Aid to Families with Dependent Children or Temporary Assistance for Needy Families) at or shortly before the beginning of the study, and $80 \%$ were receiving food stamps. Most caregivers (70\%) reported annual household incomes below \$10,000. At least $20 \%$ reported that they had difficulty buying food for their families and paying rent; nearly $40 \%$ reported difficulty paying electric and heating bills and buying clothes for their children at Time 1 .

In-home services caseworkers reported that more than one-third (37\%) of the caregivers had problems with alcohol or other drugs. Caregivers' average score on the SCL-90-R depression subscale $(\sim 1)$ was between norms for outpatient clinical and nonclinical samples of adult women (Derogatis, 1994).

\section{Caseworkers}

Most (70\%) of the FPS and SCOH caseworkers were female, $66 \%$ were AfricanAmerican, and $43 \%$ had some graduate-level education. On average they had approximately 9 years of experience in social work, and 5 to 6 years of professional experience in child welfare (mean=5.48, sd=5.86). Their "usual" caseload size (in FPS or SCOH) was 7 (mean=6.59, $\mathrm{sd}=3.93$, range $=0$ to 15$)$.

\section{Caseworker Contacts}

On average, caregivers had about 1.33 in-person contacts with FPS or SCOH caseworkers before the first interview ( $\mathrm{sd}=2.47$, range $=0$ to 16 ), 8.69 contacts between Time 1 and Time 2 
$(\mathrm{sd}=11.16$, range $=0$ to 60$)$, and 1.69 contacts between Time 2 and Time $3(\mathrm{sd}=3.71$, range $=0$ to 24). The average across waves was 6.29 contacts.

Prior to Time 2, caregivers who received FPS services had significantly more contacts (as defined above) with caseworkers than those who received $\mathrm{SCOH}$ services, but there was also more variation in contacts within the FPS group than among families who received SCOH (FPS mean=16.48, $\mathrm{sd}=1.19 ; \mathrm{SCOH}$ mean=5.69, $\mathrm{sd}=.51 ; \mathrm{t}=8.34, \mathrm{p}<.001)$. Between Time 2 and Time 3 there were no significant differences between groups in the number of caseworker contacts (FPS mean=1.85, $\mathrm{sd}=.36 ; \mathrm{SCOH}$ mean=1.66, $\mathrm{sd}=.23 ; \mathrm{t}=-.45 ; \mathrm{p}=.65)$. Our preliminary analysis showed that treatment group (a dummy variable coded $0=\mathrm{SCOH}, 1=\mathrm{FPS}$ ) was not related to PR or ITC at any point in time or related to changes in these measures over time (results available from first author). For this reason, and because there were substantial differences in the number of contacts within and between groups, we used estimated numbers of contacts rather than service group in this analysis.

\section{Variance Decomposition}

Results of fully-unconditional HLMs (Table 3) show that most of the variance in PR and ITC scores is attributed to change over time within cases $(58.5 \%$ of the total variance in PR scores and $73.3 \%$ of the variance in ITC scores is associated with change over time). As indicated above, we did not expect these scores to be stable over time; in fact, many caseworkers hoped that PR and ITC would be changed (i.e., enhanced) by their interventions. It appears that ITC scores were more likely than PR scores to change over time.

A significant proportion of the variance in these scores (41.5\% and $26.6 \%$, respectively) is attributed to differences between cases (at level 2). There is little variance in these scores at 
level 3, indicating that caseworkers do not account for significant, overall variations in these measures.

[Table 3 here]

\section{Growth Models}

Results of three-level conditional growth models are shown in Table 4. Predictor variables associated with criterion measures at $\mathrm{p}<.1$ remain in these models. Positive life events, caregivers' single parent status, network size, economic problems, and the number of prior substantiated reports of child maltreatment were not associated with PR or ITC. Caseworker education and caseload size also were not associated with PR or ITC. In the growth models, social desirability bias (denybad) scores were not associated with PR or ITC, but this measure remains in the models as a control variable.

[Table 4 here]

\section{Problem Recognition}

Time-varying predictors. In the growth model for PR, the negative coefficient for Time 2 (-.09) suggests that, contrary to our predictions, there was a slight decrease in PR scores between Time 1 and Time 2; however, this was not significant. Similarly, there was no significant overall change in PR from Time 2 to Time 3 (coeff. $=.07)$. Thus, the changes over time $(58.5 \%$ of the variance) in PR must be due to random or nonrandom variations, not overall trends.

More recent negative life experiences and the severity of caregiver depression were associated with significantly higher PR scores at all three points in time. The number of recent caseworker contacts was not related to PR.

Case-level predictors. Initial PR scores (case means) were negatively associated with 
network support and housing problems. This suggests that problem recognition was greater among caregivers with less network support and fewer housing problems.

None of the case characteristics in our analysis predicted changes in PR scores from Time 1 to Time 2 or Time 2 to Time 3.

Caseworker-level predictors. Although caseworkers' child welfare experience had no overall effect on PR scores, those with greater experience tended to have clients whose PR scores increased between Time 1 and Time $2(\mathrm{p}<.1)$.

Taken together, the predictor variables accounted for only $6.7 \%$ of the variation in PR scores.

\section{Intentions to Change}

Time-varying predictors. The model for ITC shows that these scores tended to decrease between Time 1 and Time 2 (coeff. = -.09), followed by a slight increase to Time 3 (coeff. $=.04)$, but these trends were not significant ( $\mathrm{p}>.1$ ). Greater caregiver depression was associated with higher ITC scores at all points in time.

Case-level predictors. Younger caregivers tended to show greater initial intentions to change than older caregivers. Caregivers who had more children than others tended to have relatively high initial ITC scores (coeff. $=.07)$, but their ITC scores were likely to drop from Time 1 to Time 2 (coeff. $=-.12$ ), perhaps as a function of statistical regression toward the mean. Caregivers whose children had been removed from them before demonstrated significant increases in ITC (coeff. $=.46$ ) from Time 1 to Time 2.

Caseworker-level predictors. Caseworkers' child welfare experience was associated with slightly lower initial levels of ITC (coeff. $=-.02$ ), but appeared to have a positive, interactive 
effect with more contact. That is, greater child welfare experience was associated with a significant increase in the slope (representing more positive effects) of the frequency of contacts on ITC.

This model explains a small proportion $(9.4 \%)$ of the variance in ITC scores.

\section{Discussion}

Building on existing theory and research, we identified correlates of two components of readiness for change in a sample of caregivers who were receiving in-home services. These components of readiness, problem recognition (PR) and intentions to change (ITC), were not related in our sample.

Following Ripple and colleagues (1964), we expected certain sources of caregiver discomfort to be associated with PR. As indicated above, severity of caregiver depression, negative life events, and lack of social support were associated with greater PR, but economic and housing problems were not.

Also following Ripple and colleagues, we expected ITC to be associated with sources of discomfort and hope that the situation could be improved. We thought caregiver burden and other responsibilities might interfere with ITC. As predicted, younger caregivers had higher ITC scores than older parents. Contrary to our predictions, single parents did not have lower ITC scores than others. Caregivers with more children showed reductions in ITC scores over time, providing some support for the hypothesis that additional responsibilities may compete with ITC; on the other hand, statistical regression (the tendency of initially high scores to "regress" toward the average score) explains this finding as well.

We expected, but did not find, overall increases in PR and ITC over the first 4 months of 
in-home services. The absence of an overall trend suggests that in-home services did not have uniform effects on PR and ITC. Since there was considerable variation in these measures over time, it appears that some caregivers experienced increases and others experienced decreases in PR and ITC in the first 4 months and also in the remainder of the year following referral for inhome services.

Contrary to our predictions, the number of prior, substantiated reports of maltreatment was not associated with PR or ITC. Prior placements were related to significant increases in ITC during the first 4 months of in-home services. Perhaps the discomfort of having a child in an outof-home placement increased some caregivers' motivation to change.

Aside from its initial negative association with PR, social support was not related to change over time in PR or ITC. Frequency of contact with caseworkers had no overall effect on PR or ITC, but the caseworkers' child welfare experience was positively associated with changes in PR between Time 1 and Time 2, and frequent contact with an experienced caseworker was associated with overall increases in ITC.

Overall, our results suggest that PR and ITC fluctuate over time and vary between cases in some systematic ways, although our analysis leaves much of this variance unexplained. Case characteristics in our analysis explained less than 10 percent of the variance in PR and ITC. Caseworker experience accounted for less than 1 percent of the variance. In contrast, stronger caseworker effects were found in a study of caregiver compliance in home-based child welfare services (Littell \& Tajima, 2000) and in relation to outcomes of brief motivational interventions (Burke, Arkowitz \& Dunn, 2002).

Finally, results of the present study provide some support for the hypothesis that PR and 
ITC are separate components of readiness for change (Littell \& Girvin, 2005, 2006). PR and ITC were related to different case characteristics, and might be affected by caseworker experience and contact in different ways.

\section{Limitations}

It is important to note that these results are essentially correlational in nature and cannot be used to determine whether there are causal relationships between variables, let alone establish the direction of causality. For example, it may be that greater problem recognition led to more severe depression or vice versa--or that other factors accounted for the relationship between these variables.

Since our study was nested in a larger, controlled study of the effects of in-home services, some of the measures needed for the present analysis were less than ideal. In particular, we would have liked better data on the frequency of caseworker contacts and the nature of casework activities. The URICA scale was not ideal, because it is based on a stage theory that did not hold up in our data (Littell \& Girvin, 2006) and contains problems with item construction and scoring (Carey et al., 1999; Littell \& Girvin, 2002). Our study was based on a subsample of the EFPRS study, and results may not be generalizable to the full sample or to any larger population.

\section{Implications for Practice and Program Development}

The constructs of problem recognition and intentions to change are important to child welfare professionals (DePanfilis, 2000), but little is known about the nature of PR and ITC, whether and how these phenomena respond to treatment, and whether it is important to try to increase PR and ITC in order to bring about change in child welfare cases.

Girvin (2002) suggested that readiness for change may depend on the nature of presenting 
problems and the contexts in which these problems occur. Since many caregivers face multiple problems, their recognition of salient issues and ability to address these issues may be quite uneven across problem domains. Caregivers may recognize and handle intra-personal (e.g., emotional), social, economic, and environmental problems in different ways. For this reason, we have suggested that caregivers should not be pigeon-holed into global stages or categories of readiness for change (Littell \& Girvin, 2004). A more nuanced and potentially useful view of problem recognition is provided by Leventhal and colleagues (Leventhal, Lambert, Diefenbach \& Leventhal, 1997), who suggest that the "problem domain," as the client sees it, consists of a set of assumptions about the nature, causes, course, and potential remedies for a given problem.

Intentions to change are complex and should not be confused with willingness to work with a particular caseworker or participate in a particular program. Kazdin and colleagues (Kazdin et al., 1997) note that clients' perceptions of the efficacy, difficulty, and demands of an intervention can impede or facilitate participation in treatment. Our society tends to hold caregivers responsible for their children's living conditions, but caregivers' readiness and efforts to change may be relevant only in relation to certain kinds of problems (e.g, physical abuse, inadequate supervision) and irrelevant in relation to others (e.g., inadequate housing, poverty).

Practitioners should conduct careful assessments of caregivers' views of the presenting problems, goals and values, level of discomfort with the status quo, hope that the situation can be improved, and views of available alternatives. DePanfilis (2000) provides useful recommendations in this regard.

\section{Directions for Future Research}

Further work is needed to develop better measures of problem recognition and intentions 
to change. Our research adds to the body of evidence that suggests the URICA taps dimensions other than the stages it was designed to assess. Investigators can use concepts from theories of self-regulatory systems (Leventhal et al., 1997), barriers to treatment participation (Kazdin et al., 1997), and motivation to change (Ripple et al., 1964) to develop better measures of PR and ITC.

Future research should consider whether and how clinicians' experience and skills, and the nature and frequency of contact with clients can affect problem recognition and intentions to change. Additional work is needed to replicate our finding that the impact of frequent contact (on intentions to change) was moderated by caseworkers' experience.

Finally, in future studies, it will be important to assess whether PR and ITC matter in terms of the kinds of behavioral changes clinicians seek in cases of child maltreatment. When the presenting problem is not related to parenting behavior, PR and ITC may be irrelevant (Littell \& Girvin, 2004). However, even when behavioral change is desired, problem recognition and intentions to change are not always necessary precursors. Changes in PR and ITC may be important when they predict improvements in children's well-being. 


\section{References}

Bandura, A. (1997). Self-efficacy: The exercise of control. New York: W.H. Freeman.

Bandura, A. (1998). Health promotion from the perspective of social cognitive theory. Psychology and Health, 13, 623-649.

Bryk, A. S., \& Raudenbush, S. W. (2002). Hierarchical linear models, $2^{\text {nd }}$ edition. Thousand Oaks, CA: Sage.

Burke, B. L., Arkowitz, H., \& Dunn, C. (2002). The efficacy of motivational interviewing and its adaptations: What we know so far. In W. R. Miller \& S. Rollnick (Eds.), Motivational interviewing: Preparing people for change, $2^{\text {nd }}$ edition (pp. 217-250). New York: Guilford.

Carbonari, J. P., DiClemente, C. C., Addy, R., \& Pollak K. (1996, March). Alternate short forms of the Alcohol Readiness to Change Scale. Paper presented at the Society for Behavioral Medicine, Washington. D.C.

Cardinal, B. J. (1997). Construct validity of stages of change for exercise behavior. American Journal of Health Promotion, 12, 68-74.

Carey, K. B., Purnine, D. M., Maisto, S. A., \& Carey, M. P. (1999). Assessing readiness to change substance abuse: A critical review of instruments. Clinical Psychology: Science and Practice, 6, 245-266.

Davidson, R. (1998). The transtheoretical model: A critical overview. In W. R. Miller \& N. Heather (Eds.), Treating addictive behaviors, $2^{\text {nd }}$ edition (pp. 25-38). New York: Plenum Press.

DePanfilis, D. (2000). How do I assess a caregiver's motivation and readiness to change? In H. Dubowitz \& D. DePanfilis (Eds.), Handbook for child protection practice (pp. 324-328). Thousand Oaks, CA: Sage.

Derogatis, L. (1994). SCL-90-R Symptom Checklist 90-R: Administration, scoring, and procedures manual. Minneapolis, MN: National Computer Systems, Inc.

DiClemente, C. C., \& Prochaska, J. O. (1998). Toward a comprehensive, transtheoretical model of change: Stages of change and addictive behaviors. In W. R. Miller \& N. Heather (Eds.), Treating addictive behaviors, $2^{\text {nd }}$ edition (pp. 3-24). New York: Plenum Press.

Gelles, R. J. (1995). Using the transtheoretical model of change to improve risk assessment in cases of child abuse and neglect. Paper presented at the Fourth International Family 
Violence Research Conference, University of New Hampshire, Durham, NH, July 22, 1995.

Gelles, R. J. (1996). The book of David: How preserving families can cost children's lives. New York: Basic Books.

Gelles, R. J. (2000). Treatment-resistant families. In R.M. Reece (Ed.), Treatment of child abuse: Common ground for mental health, medical, and legal practitioners (pp. 304-312). Baltimore: The Johns Hopkins University Press.

Girvin, H. (2002). Readiness for change in a child welfare sample. Unpublished doctoral dissertation, Bryn Mawr College.

Hemphill, J. F., \& Howell, A. J. (2000). Adolescent offenders and stages of change. Psychological Assessment, 12, 371-381.

Hutchison, L. (1996). Application of the transtheoretical model's stages and processes of change in predicting treatment attrition among substance abusers. Unpublished doctoral dissertation, University of Memphis.

Isenhart, C. E. (1994). Motivational subtypes in an inpatient sample of substance abusers. Addictive Behavior, 19, 463-475.

Jefferson, L. V. (1991). The relationship between stages of change and dropout from treatment among addicted clients in an outpatient addictions treatment program. Unpublished doctoral dissertation, University of Maryland, College Park.

Kazdin, A. E., Holland, L., \& Crowley, M. (1997). Family experience of barriers to treatment and premature termination from child therapy. Journal of Consulting and Clinical Psychology, 65, 453-463.

Leventhal, H., Lambert, J. F., Diefenbach, M., \& Leventhal, E. A. (1997). From compliance to social-self-regulation: Models of the compliance process. In B. Blackwell (Ed.), Treatment Compliance and the Therapeutic Alliance. Amsterdam: Harwood Academic Publishers.

Littell, J. H., \& Girvin, H. (2002). Stages of change: A critique. Behavior Modification, 26, 223273.

Littell, J. H., \& Girvin, H. (2004). Ready or Not: Uses of the stages of change model in child welfare. Child Welfare, 83, 341-367.

Littell, J. H., \& Girvin, H. (2005). Caregivers' readiness for change: Predictive validity in a child 
welfare sample. Child Abuse \& Neglect, 29, 59-80.

Littell, J. H., \& Girvin, H. (2006). Readiness for change among primary caregivers of maltreated children. Manuscript under review.

Littell, J. H., \& Reynolds. W. W. (2002). Social desirability bias in reports of primary caregivers of maltreated children. Manuscript under review.

Littell, J. H., \& Tajima, E. A. (2000). A multilevel model of client participation in family preservation services. Social Service Review, 73, 405-435.

McConnaughy, E. A., Prochaska, J. O., \& Velicer, W. F. (1983). Stages of change in psychotherapy: Measurement and sample profiles. Psychotherapy: Theory, Research, and Practice, 20, 368-375.

McConnaughy, E. A., DiClemente, C. C., Prochaska, J. O., \& Velicer, W. F. (1989). Stages of change in psychotherapy: A follow-up report. Psychotherapy, 26, 494-503.

Miller, W. R. (1985). Motivation for treatment: A review with special emphasis on alcoholism. Psychological Bulletin, 98, 84-107.

Miller, W. R., \& Rollnick, S. (2002). Motivational interviewing: Preparing people to change, $2^{\text {nd }}$ edition. New York: Guilford.

Miller, W. R., \& Tonigan, J. S. (1996). Assessing drinkers' motivation for change: The stages of change readiness and treatment eagerness scale (SOCRATES). Psychology of Addictive Behaviors, 10, 81-89.

O'Hare, T. (1996a). Readiness for change: Variation by intensity and domain of client distress. Social Work Research, 20, 13-17.

O'Hare, T. (1996b). Court-ordered versus voluntary clients: Problem differences and readiness for change. Social Work, 41, 417-422.

Paulhus, D. L. (1984). Two-component models of socially desirable responding. Journal of Personality and Social Psychology, 46, 598-609.

Prochaska, J. O., \& DiClemente, C. C. (1984). The transtheoretical approach: Crossing traditional boundaries of therapy. Malabar, FL: Krieger Publishing Co.

Prochaska, J. O., \& DiClemente, C. C. (1986). Toward a comprehensive model of change. In W. R. Miller \& N. Heather (Eds.), Toward a comprehensive model of change. New York: Plenum Press. 
Prochaska, J. O., \& DiClemente, C. C. (1992). Stages of change in the modification of problem behaviors. In M. Hersen, R. Eisler \& P. M. Miller (Eds.), Progress in Behavior Modification, Vol. 28, New York, NY: Academic Press.

Prochaska, J. O., \& DiClemente, C. C. (1998). Comments, criteria, and creating better models: In response to Davidson. In W. R. Miller \& N. Heather (Eds.), Treating addictive behaviors, $2^{\text {nd }}$ edition (pp. 39-45). New York: Plenum Press.

Prochaska, J. O., Velicer, W. F., Rossi, J. S., Goldstein, M. G., Marcus, B. H., Rakowski, W., Fiore, C., Harlow, L. L., Redding, C. A., Rosenbloom, D., \& Rossi, S. (1994). Stages of change and decisional balance for 12 problem behaviors. Health Psychology, 13, 39-46.

Project MATCH Research Group. (1997). Matching alcoholism treatments to client heterogeneity: Project MATCH posttreatment drinking outcomes. Journal of Studies on Alcohol, 58, 7-29.

Raudenbush, S., Bryk, A., Cheong, Y. F., \& Congon, R. (2001). HLM 5: Hierarchical linear and nonlinear modeling. Lincolnwood, IL: Scientific Software International.

Reisma, R. P., Pattenden, J., Bridle, C., Sowden, A. J., Mather, L., Watt, I. S., \& Walker, A. (2002). A systematic review of the effectiveness of interventions based on a stages-ofchange approach to promote individual behaviour change. Health Technology Assessment, 6 (24).

Reynolds, W. M. (1982). Development of reliable and valid short forms of the Marlowe-Crowne Social Desirability Scale. Journal of Clinical Psychology, 38, 119-125.

Rollnick, S., Heather, N., Gold, R., \& Hall, W. (1992). Development of a short "readiness to change" questionnaire for use in brief, opportunistic interventions among excessive drinkers. British Journal of Addiction, 87, 743-754.

Ripple, L., Alexander, E., \& Polemis, B. (1964). Motivation, capacity, and opportunity: Studies in casework theory and practice. Chicago: University of Chicago Press

Sutton, S. (1996). Can "stages of change" provide guidance in the treatment of addictions? A critical examination of Prochaska and DiClemente's model. In G. Edwards \& C. Dare (Eds.), Psychotherapy, psychological treatments and the addictions (pp. 189-205). Cambridge: Cambridge University Press.

Velasquez, M. M., Carbonari, J. P., \& DiClemente, C. C. (1999). Psychiatric severity and behavior change in alcoholism: The relation of the transtheoretical model variables to psychiatric distress in dually diagnosed patients. Addictive Behaviors, 24, 481-496. 
Westat, Inc. (2001). Evaluation of family preservation and reunification programs: Interim report. Washington, DC: U.S. Department of Health and Human Services' Assistant Secretary for Planning and Evaluation. Available at: http://aspe.os.dhhs.gov/hsp/fampres94/index.htm

Westat, Inc. (2002). Evaluation of family preservation and reunification programs: Final report. Washington, DC: U.S. Department of Health and Human Services' Assistant Secretary for Planning and Evaluation. Available at: http://aspe.os.dhhs.gov/hsp/fampres94/index.htm

Weinstein, N. D., Rothman, A. J., \& Sutton, S. R. (1998). Stage theories of health behavior: Conceptual and methodological issues. Health Psychology, 17, 290-299.

Willoughby, F. W., \& Edens, J. F. (1996). Construct validity and predictive utility of the stages of change scale for alcoholics. Journal of Substance Abuse, 8, 275-291. 
Table 1: Descriptive Data on Problem Recognition and Intentions to Change

\begin{tabular}{|c|c|c|c|c|c|c|c|c|c|}
\hline \multirow[b]{2}{*}{ Scales } & \multicolumn{3}{|c|}{ Time $1(\mathrm{~N}=258)$} & \multicolumn{3}{|c|}{ Time $2(\mathrm{~N}=252)$} & \multicolumn{3}{|c|}{ Time $3(\mathrm{~N}=221)$} \\
\hline & Mean & $(\mathrm{sd})$ & Alpha & Mean & (sd) & Alpha & Mean & (sd) & Alpha \\
\hline Problem Recognition (PR) & 3.63 & $(.68)$ & .65 & 3.64 & $(.72)$ & .71 & 3.52 & $(.71)$ & .71 \\
\hline Intentions to Change (ITC) & 3.95 & $(.68)$ & .91 & 3.90 & $(.63)$ & .88 & 3.83 & $(.66)$ & .89 \\
\hline
\end{tabular}

Note: PR = mean of 6 reverse-scored Precontemplation items; ITC $=$ mean of 12 items $(6$ Contemplation and 6 Action items). Responses were provided on a 5-point scale, where $1=$ strongly disagree, $2=$ disagree, $3=$ undecided, $4=$ agree, $5=$ strongly agree. 
Table 2: Descriptive Data on Predictor Variables, by Level

\begin{tabular}{|c|c|c|c|c|c|}
\hline & Scoring & Mean & $\mathrm{SD}$ & Min & $\operatorname{Max}$ \\
\hline \multicolumn{6}{|c|}{ Time-varying Predictors (Level 1, N=423 observations) } \\
\hline $\begin{array}{l}\text { Positive life events in past } \\
3 \text { months }\end{array}$ & $\begin{array}{l}\text { proportion of } 6 \text { items } \\
\text { endorsed }\end{array}$ & .18 & .17 & 0 & .93 \\
\hline $\begin{array}{l}\text { Negative life events in past } \\
3 \text { months }\end{array}$ & $\begin{array}{l}\text { proportion of } 8 \text { items } \\
\text { endorsed }\end{array}$ & .07 & .11 & 0 & .63 \\
\hline Caregiver depression & mean of 13 SCL-90-R items & .98 & .86 & 0 & 3.85 \\
\hline Caseworker contacts & Count & 6.29 & 9.26 & 0 & 60 \\
\hline \multicolumn{6}{|c|}{ Case Characteristics (Level 2, $N=163$ cases) } \\
\hline Caregiver age & Years & 32.13 & 9.01 & 19.13 & 75.62 \\
\hline Number of children & Count & 3.38 & 1.77 & 1 & 10 \\
\hline Single parent & dummy (1=yes) & .53 & & 0 & 1 \\
\hline $\operatorname{MCSDS}^{\mathrm{a}}$ denybad score & Standardized mean of 8 items & -.06 & .98 & -2.94 & 1.20 \\
\hline Prior maltreatment reports & Count & 1.19 & .93 & 0 & 5 \\
\hline Prior placement & $\begin{array}{l}\text { dummy }(1=\text { any prior } \\
\text { placement })\end{array}$ & .18 & & 0 & 1 \\
\hline Network size & Count & 4.76 & 2.46 & 0 & 12 \\
\hline Network support & proportion & .81 & .28 & 0 & 1 \\
\hline Housing problems & $\begin{array}{l}\text { proportion of } 10 \text { items } \\
\text { endorsed }\end{array}$ & .10 & .15 & 0 & .70 \\
\hline Economic problems & $\begin{array}{l}\text { proportion of } 4 \text { items } \\
\text { endorsed }\end{array}$ & .32 & .32 & 0 & 1 \\
\hline \multicolumn{6}{|c|}{ Caseworker Characteristics (Level 3, N=44 caseworkers) } \\
\hline Years CW experience & Count & 5.48 & 5.86 & 0 & 26 \\
\hline Some graduate study & dummy (1=yes) & .43 & & 0 & 1 \\
\hline Caseload size & Count & 6.59 & 3.93 & 0 & 15 \\
\hline
\end{tabular}

${ }^{\mathrm{a}}$ MCSDS $=$ Marlowe Crowne Social Desirability Scale 
Table 3: Variance Decomposition (Results of Fully Unconditional HLMs; N=423 observations, 163 cases, 44 caseworkers)

\begin{tabular}{|c|c|c|c|c|c|c|c|c|c|c|}
\hline \multirow[b]{2}{*}{ Level } & \multicolumn{5}{|c|}{ Problem Recognition } & \multicolumn{5}{|c|}{ Intentions to Change } \\
\hline & $\begin{array}{r}\text { Var. } \\
\text { Comp. }\end{array}$ & $\begin{array}{l}\% \text { of } \\
\text { Total }\end{array}$ & $X^{2}$ & (df) & Sig. & $\begin{array}{r}\text { Var. } \\
\text { Comp. }\end{array}$ & $\begin{array}{l}\% \text { of } \\
\text { Total }\end{array}$ & $X^{2}$ & (df) & Sig. \\
\hline 1 (Time) & .614 & 58.5 & & & & .742 & 73.3 & & & \\
\hline 2 (Case) & .435 & 41.5 & 465.74 & (119) & $* * *$ & .270 & 26.6 & 314.74 & (119) & $* * *$ \\
\hline $3(\mathrm{Wkr})$ & $<.001$ & $<.1$ & 33.57 & $(43)$ & & $<.001$ & $<.1$ & 32.27 & $(43)$ & \\
\hline
\end{tabular}


Table 4: Results of Conditional Piecewise Linear Growth Models

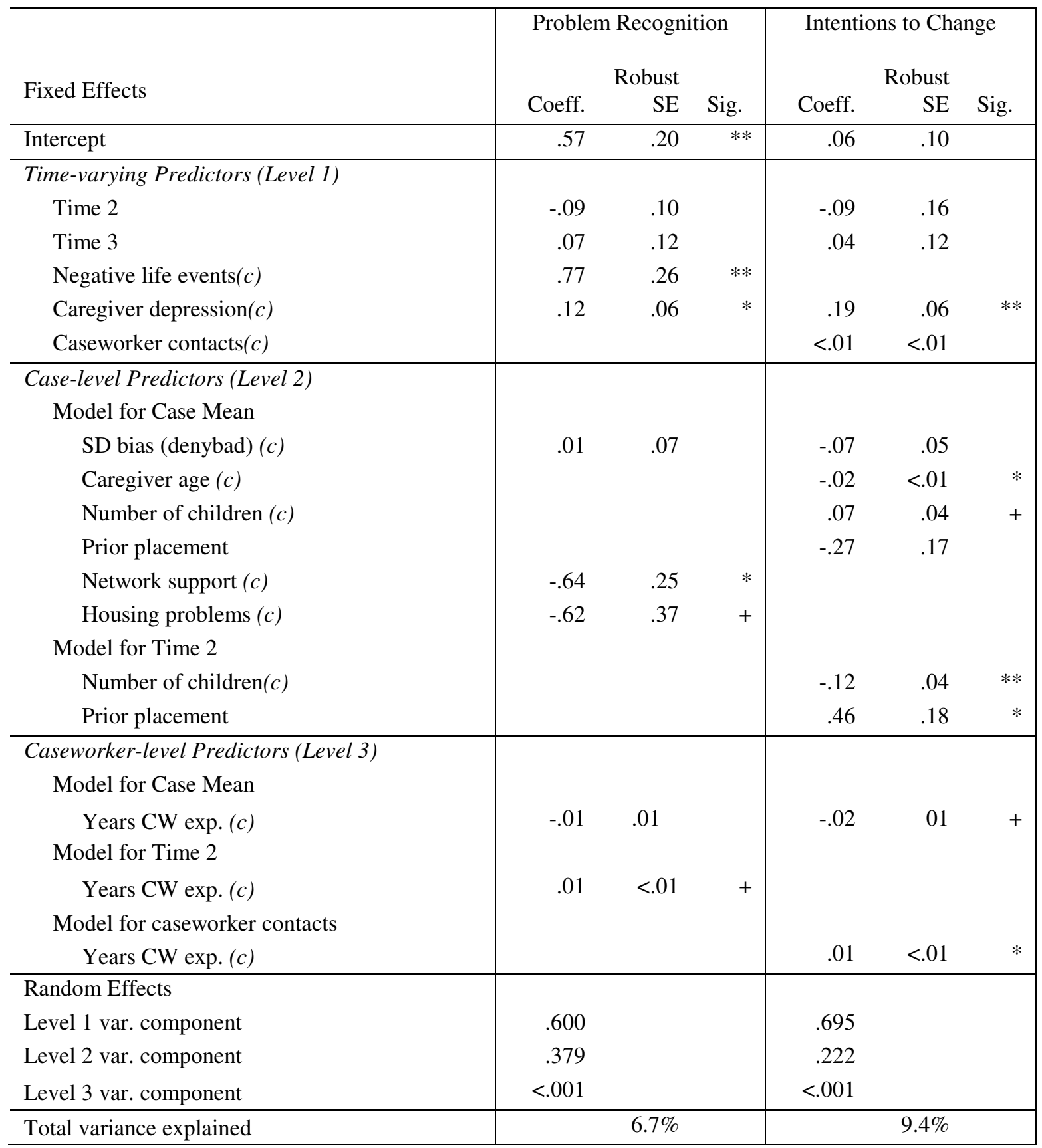

(c) = variable centered around its grand mean.

$+=\mathrm{p}<.1, *=\mathrm{p}<.05, * *=\mathrm{p}<.01, * * *=\mathrm{p}<.001$ 